\title{
SOBRE MENINOS E SOLDADOS: HOMOEROTISMO E SUBVERSÃO DE PAPÉIS DE GÊNERO NUMA RELEITURA CONTEMPORÂNEA DA PRIMEIRA GUERRA MUNDIAL
}

Denise Borille de Abreu (PUCMINAS)

\begin{abstract}
Numa estação de trem, as enfermeiras A grandes penas com a água da torneira, seus véus, véus num convento,

Tocam os seus feridos, Os homens, o sangue que ainda flui Pernas e braços empilhados lá fora A tenda dos gritos sem fim Um hospital de bonecas.
\end{abstract} (PLATH, Sylvia, "Chegando Lá", Ariel ,1965, tradução minha)

Resumo: O ano de 2014 marca o centenário de eclosão da Primeira Guerra Mundial e, das várias possibilidades de releituras contemporâneas desse evento, destaca-se o romance Regeneration (1991), da escritora inglesa Pat Barker. A narrativa ficcionaliza as conversas que teriam acontecido entre três poetas de guerra ingleses (Wilfred Owen, Siegfried Sassoon e Robert Graves) durante a estada dos mesmos no Hospital Craiglockart's - um hospital de guerra para tratamento psiquiátrico de oficiais do exército britânico, localizado na Escócia. Enfoque especial é dado para uma suposta relação entre Owen e Sassoon. Este artigo aborda, de maneira mais enfática, como os papéis tradicionais de gênero são renegociados na metaficção de Pat Barker. No hiato entre dois extremos, a história é regenerada: os homens expõem sua fragilidade, as mulheres trabalhadoras conquistam direitos iguais aos dos homens e a roda dinâmica da história parece engendrar uma evolução em rumo a novos caminhos para a humanidade.

Palavras-chave: Escrita biográfica, Ficção inglesa contemporânea, Escrita feminina da Primeira Guerra Mundial, Estudos de gênero, Teoria do trauma. 
Abstract: 2014 will mark one hundred years since the outbreak of the First World War. Among several contemporary re-readings of such event, Pat Barker's novel Regeneration (1991) emerges as a remarkable contemporary example. The novel fictionalizes the conversations held by three war poets who wrote and fought in the First World War (Wilfred Owen, Siegfried Sassoon, and Robert Graves) during their stay at Craiglockart's Hospital - a war hospital for the treatment of shellshocked officers, in Scotland. Special emphasis is given to an assumed relationship between Owen and Sassoon. The article addresses, more emphatically, how traditional male and female roles are renegotiated in Barker's metafiction. In the gap between two extremes, history is regenerated: men disclose their frailty, women workers gain equal rights as men's, and history's dynamics generates an evolution towards new directions for humankind.

Keywords: Life Writing, English Contemporary Fiction, Women Writing of the First World War, Gender Studies, Trauma Theory.

\section{INTRODUÇÃO: NEGOCIANDO PAPÉIS DE GÊNERO}

Por mais que pareça paradoxal, alguns papéis de gêneros tradicionais e arquetípicos parecem ter sido subvertidos pela Primeira Guerra, o que acabou por contribuir para uma evolução dos papéis sociais das mulheres. Por um lado, a fragilidade emocional, assim como a vulnerabilidade psicológica dos homens, era explicitada em narrativas femininas de guerra, tais quais The Return of the Soldier, de Rebecca West, e no romance Regeneration, de Pat Barker. Por outro lado, algumas mulheres começavam a trabalhar como ativistas políticas, voluntárias da Cruz Vermelha, motoristas de ambulância, jornalistas e funcionárias em fábricas de munições, para citar alguns dos 
exemplos encontrados em testemunhos de mulheres. Outras, por sua vez, evoluíram da condição de vítimas caladas à de pensadoras proativas, como nos mostra Vera Brittain, em seu relato autobiográfico Testament of Youth, e Virginia Woolf, em seu romance Mrs. Dalloway. As contribuições literárias de Virginia Woolf, Vera Brittain, Rebecca West e Pat Barker são revestidas de um significado histórico preciso e latente e, juntas, adquirem um papel importante na construção da memória cultural da Primeira Guerra.

Em Regeneration, uma ficção contemporânea de Pat Barker, de 1991, são sugeridas várias implicações psicológicas, sobretudo no que diz respeito à interposição de papeis masculinos e femininos. Os soldados combatentes eram enviados ao Hospital Craiglockart, na Escócia, para tratamento psiquiátrico e sofriam, acima de tudo, por ter que revelar e compartilhar as suas experiências terríveis, vivenciadas durante a guerra. Isso se dava, em boa parte, porque no Exército,

eles haviam sido treinados a identificar a repressão emocional como a essência da masculinidade. Os homens que entrassem em crise, chorassem ou admitissem ter medo eram considerados afeminados ou fracassados, ao contrário dos homens de verdade. (BARKER, 1991, p. 48 , tradução minha) 
Curiosamente, as relações entre os soldados, baseadas principalmente na camaradagem, assim como os contatos entre médico e pacientes, sugerem, na narrativa de Barker, que o comportamento daqueles homens intercalava-se como ora masculino, ora feminino. Os cuidados e o carinho do doutor Rivers para com o soldado Prior, por exemplo, é definido como uma atitude tipicamente feminina e representa, nas palavras do médico: “Um - dos muitos - paradoxos da guerra era que o mais brutal dos conflitos propiciasse uma relação entre os oficiais e os homens que era... doméstica. Carinhosa. Layard sem dúvida teria dito: Materna.". (BARKER, 1991, p. 107, tradução minha). Note-se que o uso de reticências, que precede a palavra "doméstica", sinaliza uma hesitação. O uso do adjetivo "Carinhosa", em uma posição isolada entre dois pontos finais, dá a impressão que algo vergonhoso estivesse sendo declarado. A palavra mais pungente aparece no final, "Materna", como se estivesse sendo proferida por uma voz alheia, distante. Santanu Das esclarece que:

É uma grande ironia pensar que a primeira guerra industrial mundial, que castigou o corpo masculino em uma escala enorme, também acalentou o mais intenso dos laços humanos... uma ordem muito diferente da experiência masculina, que incluía medo, vulnerabilidade, apoio e ternura física, ganhava espaço. (DAS, 2006, p. 135, tradução minha) 
Note que a afirmativa de Das salienta o comportamento homossocial gerado, em grande parte, pela guerra - maior proximidade entre os homens nos exércitos, o apoio, a exposição de sentimentos e a ternura advindos desse encontro entre pessoas do mesmo sexo.

Apesar de um presumido disparate entre atitudes emocionais de homens e mulheres, o romance revela como ambos os papéis se intercalam em alguns dos pacientes em Craiglockart. O poeta inglês, e também combatente, Siegfried Sassoon, tem a admiração do doutor Rivers pelo "[a]mor que tinha por seus homens. A necessidade que tinha de provar sua coragem. De uma forma racional, ele já havia provado isso várias vezes, mas depois a necessidade deixou de ser inteiramente racional". (BARKER, 1991, p. 118, tradução minha). Um sentimento tal qual o amor que Sassoon tinha em treinar os seus homens poderia ser entendido emocionalmente, mas nunca explicado racionalmente pelo doutor Rivers. As razões pelas quais grande parte dos soldados experimentam a susceptibilidade emocional são, de acordo com Das:

Porque a guerra passa a incluir a sexualidade em um conjunto de emoções como vulnerabilidade, desespero, medo e a necessidade universal de ser amado e cuidado: no encontro dos "lábios", o 
erotismo da ganância é superado pelas declarações de afeto. Além de exaltar... o amor gay das trincheiras, isso deve ser interpretado dentro de um contexto de mutilação e mortalidade iminentes. (DAS, 2006, p. 136, tradução minha)

Essa afirmativa de Das não apenas reforça o caráter homossocial da citação anterior, como também sugere um forte comportamento homoerótico, que vem a ser amplamente explorado na estética homoerótica de Regeneration, sobretudo na relação entre o Dr. Rivers e seus pacientes, e mais especificamente entre os poetas Siegfried Sassoon e Wilfred Owen, que teriam tido um relacionamento na vida real. 0 exemplo de destaque é o beijo da morte - the kiss of death - ou a prática de despedida entre os soldados, face à proximidade com a morte, através do encontro dos lábios.

\section{E A HUMANIDADE, AFINAL, PARA ONDE CAMINHA?}

De fato, escritoras contemporâneas como Pat Barker parecem perpetuar uma tradição de escrita que remonta às moiras gregas, entidades femininas que teciam e determinavam o destino dos mortais. Além de Barker mostrar o olhar de uma mulher contemporânea sobre a Primeira Guerra Mundial, sua obra Regeneration brinda o leitor com a particularidade da sua visão sobre a (re)escrita da história. 
A autora inglesa "teceu" cerca de 600 páginas perguntando-se sobre os sofrimentos enfrentados pelos meninos soldados que foram à Primeira Guerra. Regeneration (1991) é o primeiro volume de sua trilogia sobre a Primeira Guerra Mundial, seguida de The Eye in the Door (1993) e The Ghost Road (1995). Trata-se de uma narrativa que ficcionaliza a estada do poeta de guerra inglês Siegfried Sassoon no hospital psiquiátrico de Craiglockart's, em 1917, logo após ele ter escrito "A Soldier's Declaration", protestando contra a Primeira Guerra e seu prolongamento desnecessário. Enquanto ele é atendido pelo médico psiquiatra Rivers, ao mesmo tempo inspirado na visão de Freud e na abordagem mais "ortodoxa" do Dr. Yealland, ele encontra os pacientes Robert Graves e Wilfred Owen, ambos poetas de guerra. Após oferecer conselhos valiosos a Owen sobre seu célebre poema "Anthem for Doomed Youth" (traduzido para o português como "Hino a uma Juventude Condenada"), Sassoon e o Dr. Rivers se aproximam de Billy Prior, um paciente ficcional com distúrbio de estresse póstraumático e questões homossexuais - temas complexos vivenciados por soldados da Primeira Guerra, uma vez que eram até então vistos como uma ameaça à bravura e virilidade dos soldados. Embora as tentativas humanistas do Dr. Rivers tivessem ajudado Sassoon e os outros pacientes 
a confrontar o trauma e a dor que os assombravam, podese observar que a tarefa do médico consistia em oferecer cuidado adequado a esses pacientes de forma a assegurar o retorno dos mesmos ao front de batalha.

Através do uso da ficção, os mitos e as emoções da guerra, experimentados por toda uma geração de homens, que lutaram entre 1914 e 1918, são revisitados por Barker. Talvez a característica mais peculiar dessa narrativa seja a ênfase nos sentimentos masculinos recorrentes de medo e desespero, contrários aos valores masculinos repressivos impostos aos homens daquela época. Sentimentos de vulnerabilidade, esperados principalmente das mulheres, podiam ser encontrados entre os soldados e todos os homens envolvidos em atividades militares, também. No meio da narrativa, pode-se observar que o Dr. Rivers luta contra seus impulsos de compaixão ao cuidar de um de seus pacientes, Billy Prior. O médico indaga:

Ele não gostava do termo "mãe masculina". Ele se lembrou de desgostar desse termo mesmo até então. Ele desacreditava da implicação que o ato de cuidar, mesmo quando realizado por um homem, continua a ser feminino, como se tal habilidade tivesse sido tomada de empréstimo, ou mesmo roubada, das mulheres - um tipo de equivalência moral de covardia. (BARKER, 1991, p. 107, tradução minha) 
Cumpre observar que os pensamentos de Rivers são atormentados, de um lado, por uma visão estereotipada do comportamento masculino adotada por um de seus colegas, o Dr. Layard. Por outro lado, a grande consideração que tinha por seus pacientes parece lhe impor um dilema ético: uma tendência pessoal a se sensibilizar pelo drama vivenciado por seus companheiros durante a guerra.

O fato de Rivers não ter uma explicação para seu profundo comprometimento com os homens que sofriam nas trincheiras e buscavam ajuda em Craiglockart culmina numa autoimagem "invertida", segundo a qual ele estaria agindo como uma enfermeira, e não como um médico militar. Seus pensamentos oscilam entre sentimentos de covardia e preferências sexuais, e ele se questiona sobre a semelhança entre as expressões nos rostos de seus pacientes (jovens oficiais) e uma certa representação de mulher:

Eles tinham de se preocupar com meias, botas, bolhas nos pés, comidas e bebidas quentes. E aquela expressão sempre perturbada que eles tinham. Rivers só havia visto isso em um lugar: nas alas públicas dos hospitais e nos rostos das mulheres que tinham que sustentar, sozinhas, famílias numerosas com uma renda baixa. Mulheres que, com trinta e poucos anos, aparentavam ter cinquenta ou mais. Era a expressão das pessoas que são totalmente responsáveis por vidas 
que elas não podem salvar. (BARKER, 1991, p. 107, tradução minha)

Cabe ressaltar a nitidez com a qual Rivers retrata o drama vivido pelas mulheres durante a guerra, que se estende não apenas as suas colegas enfermeiras, mas por aquelas mulheres que perdiam seus maridos precocemente por causa da guerra e tornavam-se o "ganha-pão" das famílias. Mulheres essas que, além de tudo, souberam demonstrar apoio incondicional aos homens que estavam nos campos de batalha, não obstante às várias restrições que a sociedade impunha no que dizia respeito a elas participarem diretamente da guerra.

A importância das intervenções das mulheres em favor dos soldados, na verdade, pode ser vista desde a literatura clássica - no poema de guerra fundador de Homero, a llíada, quando a deusa Tétis interfere em favor de seu filho Aquiles. Entretanto, de maneira proposital, uma das atitudes mais elucidativas da deusa mãe para com seu filho heroico não é mencionada no Canto I e sim no Canto XVIII. A passagem ilustra, de forma enfática, a inversão dos papeis tipicamente esperados dos homens e das mulheres, semelhante ao que Pat Barker faz em Regeneration.

O episódio, nesse caso, trata do sofrimento de Aquiles devido à morte de seu amado Pátroclo. A intensidade do 
seu luto é descrita com detalhes físicos ${ }^{1}$ e é tão pungente que faz com que as escravas se apiedem da dor de seu patrão: "Cativas do Peleide e de Pátroclo, as fâmulas,/ coração dolorido, ululavam, correndo/ para Aquiles, o herói mente-fremente; as mãos/ delas todas batiam no peito; joelhos frouxos,/ desmaiaram." (Ilíada 18. 28-31). Em seguida, Aquiles chora copiosamente, a ponto de seu choro ser ouvido por sua mãe, que habita no mar. Igualmente comovidas pelo sofrimento do grande guerreiro, as irmãs de Tétis, as Nereides, se sentem compelidas a acompanhar a deusa mãe até a costa de Troia, onde o filho dela está a clamar ajuda. ${ }^{2} \mathrm{O}$ movimento espacial ganha importância aqui: o grito ressoa até as profundezas do mar e a ajuda vem até a superfície. Ambos movimentos reforçam a ideia de inversão, acrescida da vulnerabilidade à dor que o grande herói sente, e que o leva a clamar pela ajuda de sua mãe. Na llíada, o exagero dessa inversão pode ser visto na longa lista contendo os nomes das Nereides (a relação completa inclui dez linhas), juntamente com o nome do

\footnotetext{
1 A tradução da llíada de Haroldo de Campos descreve a dor sentida pelo maior guerreiro grego da seguinte forma: "E a dor, nuvem-escura,/ eclipsou o herói. De ambas as mãos toma esfúmeas/ cinzas e as lança sobre a cabeça, encardindo/ o rosto belo; a túnica nectárea, tinta/ de fuligem, sujou-se; jaz no pó, estendido,/ grande, grande e espaçoso, arrancando os cabelos." (llíada 18. 22-27.)

2 Cito os seguintes versos da tradução de Haroldo de Campos: "Terrivelmente a mãe, Tétis, gritou. Sentada/ nas profundezas do mar, junto ao velho pai, tudo/ ouvira; e todas as Nereides abissais/ circum-ecoaram, lamentosas, e a rodearam." (Ibid. 35-38).
} 
local a que pertencem: "eis as Nereides/ abissais, todas; na esplendente gruta, batem-se/ no peito." Ilíada 18. 51-53. Com grande esforço as mulheres chegam à costa troiana, onde estão os navios dos Mirmidões (Ilíada 18. 69-75). Cito a descrição dramática do encontro da mãe com seu filho: "A mãe se avizinhou dele, convulso,/ em dor aguda; ecoando-Ihe a aflição, abraça-Ihe,/ maternal, a cabeça e Ihe diz, lacrimosa,/ palavras-asas: 'Por quê choras? Que te dói/ no coração? Não cales, filho.'" (Ilíada 18. 70-74).

Se não bastasse compartilhar o drama de seu filho, a mãe imortal deve, em seguida, revelar o trágico destino de seu filho na Guerra de Troia ${ }^{3}$. Aquiles aceita seu destino trágico, que Haroldo de Campos traduz diretamente do texto grego como "Moira". O único consolo que o filho de Tétis encontra é voltar à guerra e matar Hector e, assim, vingar a morte de Pátroclo, ainda que isso Ihe custe a própria vida ${ }^{4}$. Ciente do destino trágico de seu filho, Tétis ordena às Nereides que voltem para o fundo do mar, ao passo que ela sobe ao Monte Olimpo e implora a Hefesto para forjar uma armadura nova para seu filho:

3 De acordo com a seguinte passagem: "'Moira breve a tua, filho, já que assim decides./ Héctor morrendo, o Fado há de querer-te morto!'” (Ilíada 18. 95-96).

4 Grifo meu. Talvez faria mais sentido escrever "filho de Peleu", pois os homens notáveis da Grécia Antiga eram chamados por patrônimos. Nessa passagem, entretanto, dadas a proximidade e a relevância do encontro entre mãe e filho, tomei a liberdade de me referir ao bravo Aquiles como "filho de Tétis". 
Ordena às suas irmãs, deusas do marsalino:/ 'Mergulhai no regaço talássio, ao palácio,/ para o velho salino-alvo rever, o pai/ marinho, e relatar-lhe os fatos. Subo, agora, ao Olimpo. Saberei, de Hefesto, glório-artífice,/ se a meu filho armas panesplêndidas, gloriosas,/ dispõe-se a dar.' Mergulham todas sob as ondas. E Tétis, pés-de-prata, ascende à sede olímpica, buscando armas de glória para Aquiles. (Ilíada 18. 140-148)

Note a inversão de papéis e a importância da distância espacial: a deusa mãe intervém em favor de seu filho mais uma vez, e sua mediação é contrastada por opostos, "mergulham", "ascende" e outras referências contrárias de distância, tais como "regaço talássio" e "Monte Olimpo".

Em Regeneration, a inversão de papéis aparece quando Rivers se comporta não como um médico, mas como uma mãe. Aqueles de quem se espera um comportamento heroico, e que sobreviveram à guerra como soldados valentes, suplicam ajuda a seus superiores, como crianças. Enquanto Prior se entrega aos cuidados de Rivers, sua companheira, Sarah, trabalha numa fábrica de munições para sustentar a casa deles. Papéis tipicamente masculinos e femininos são invertidos, ficção e realidade se intercalam. No hiato entre dois extremos, a história é regenerada: os homens expõem sua fragilidade, as mulheres trabalhadoras 
conquistam direitos iguais aos dos homens e a roda dinâmica da história parece engendrar uma evolução em rumo a novos caminhos para a humanidade.

Uma vez investida da visão e da subjetividade contemporâneas, a história da Primeira Guerra Mundial não mais figura como um momento estanque no tempo. O que se pode observar é que a história é (re)constituída pelas experiências humanas, podendo ser (re)conhecida por gerações diferentes, em momentos distintos. Parece haver um aspecto mimético na história - em alusão a Erich Auerbach - que se regenera perpetuamente, tão inevitável como se tivesse sido cuidadosamente tramado por uma Moira, porém, nos dias atuais.

Tanto escritores quanto leitores contemporâneos, como Pat Barker em Regeneration, veem com admiração os papéis desempenhados pelas mulheres no início do século $X X$. Suas narrativas persistem no tempo e nos trazem à memória como deve ter sido duro viver na carne o momento da guerra. Através de personagens masculinas, a narrativa de Barker exemplifica a grande mudança que a Primeira Guerra Mundial causou nas relações de gênero. Karen Levenback reconhece o caráter inovador da escrita de Barker e nos lembra da legitimidade da escrita da dor 
de homens e mulheres vivenciada durante a guerra. Ela conclui que:

Outras (escritoras) ainda (como as obras revolucionárias de Lynne Hanley e Pat Barker) não distinguem os limites entre biografia, história e literatura juntas. E, tendo em vista que há vantagens óbvias para tal abordagem, existe também a possibilidade de que a ausência de limites nos priva do prazer e da percepção de percorrer a estrada sinuosa, mas sempre propositada, escolhida por Virginia Woolf para atribuir sentido a sua experiência pessoal com a guerra. (LEVENBACK, 1999, p. 05, tradução minha).

Regeneração é o termo empregado pela biologia para a substituição de um órgão danificado através da formação de um novo tecido, e que adquire um significado similar quando aplicado às narrativas femininas de guerra: que a evolução da representação histórica das mulheres, ampliada pela Primeira Guerra Mundial, ajudou a redefinir a humanidade e como - ou quem - realmente queremos ser.

\section{REFERÊNCIAS}

AUERBACH, Erich. Mimesis. São Paulo: Perspectiva,1987.

BARKER, Pat. Regeneration.). Nova York: Plume, 1991.

BRITTAIN, Vera. Testament of Youth: An Autobiographical Study of the Years 1900-1925. Londres: Penguin Books, 1994.

CAMPOS, Haroldo de. llíada de Homero: volumes I \& II. São Paulo: Editora Mandarim, 2001. 
DAS, Santanu. Touch and Intimacy in First World War Literature. Cambridge: Cambridge University Press, 2006.

GRAVES, Robert. Goodbye to All That. Londres: Penguin Classics, 2000.

LEVENBACK, Karen L. Virginia Woolf and the Great War. Nova York: Syracuse University Press, 1999.

OWEN, Wilfred. The Collected Poems of Wilfred Owen. Nova York: New Directions Publishing Corporation, 1965.

PLATH, Sylvia. Ariel: The Restored Edition. Nova York: HarperCollins, 2005. SASSOON, Siegfried. Collected Poems, 1908-1956. Londres: Faber and Faber, 1986.

WEST, Rebecca. The Return of the Soldier. Nova York: Random House,2004. WOOLF, Virginia. Mrs. Dalloway. Londres: Penguin Books, 1996.

Denise Borille de Abreu é mestre em Literaturas de língua inglesa (UFMG), onde estudou narrativas femininas britânicas da Primeira Guerra Mundial. Atualmente dedica sua pesquisa de doutorado a estudar narrativas femininas do trauma de guerra, de autoria de língua portuguesa, sobretudo aquelas que se referem à Guerra dos Farrapos e à Guerra Colonial de Moçambique. 